San Jose State University

From the SelectedWorks of Lili Luo

2015

\title{
Reference service evaluation at an African academic library: the user perspective
}

Lili Luo, San Jose State University

Viscount B. Buer, University of Education, Winneba 


\title{
Reference Service Evaluation at an African Academic Library: The User Perspective
}

\author{
Lili Luo \& Viscount Buer
}

\begin{abstract}
Purpose: This paper provides a detailed discussion of a large-scale library reference evaluation study conducted at the University of Education, Winneba (UAE) in Ghana. The study seeks to evaluate the reference service from the user perspective, focusing on how users use and perceive the service.

Design/methodology/approach: Self-administered survey was used as the data collection instrument. One thousand questionnaires were distributed to library users in a three-week period, and the response rate was $63.7 \%$.

Findings: The reference service had a high non-use rate of $42.6 \%$, which was primarily attributed to library users' self-sufficiency and lack of awareness of the service. The top three motivations for library users to use the reference service were class assignments, personal interests, and using library facilities. Although their overall altitude was positive, users felt that reference librarians were more successful at exhibiting customer service qualities than performing tasks related to identifying users' information needs and searching/locating relevant information to fulfill the needs.
\end{abstract}

Practical implications: The knowledge gained from this study will deepen the understanding of how the reference service is utilized and perceived by library users and offer insights on how to enhance the services to optimize the user experience.

Originality/value: This study yields an enriched view of reference service provision in the African context. Its findings will help other academic libraries in Africa successfully plan and implement their own reference evaluation efforts and ultimately encourage more evidence-based library practices in the developing world.

\section{Keywords}

reference, evaluation, academic libraries, Africa, Ghana

[This is the preprint. Please cite it as "Luo, L. \& Buer, V. (2015). Reference service evaluation at an African academic library: the user perspective. Library Review, 64(8/9), 553-566."] 


\section{Reference Service Evaluation at an African Academic Library: The User Perspective}

\section{Introduction}

Reference services are an integral part of library operations. To ensure the success of reference services, it's important to conduct evaluations to identify existing problems or deficiencies, and make adjustments accordingly to improve the service. Evaluation efforts are essential because they provide the library administration and the reference service itself with information about how well the service is meeting its intended goals, objectives, and outcomes, the degree to which the service is meeting user needs, and if resources being committed to the service are producing the desired results. In addition, evaluation data provide a basis for the reference service to report and communicate to the broader library, user, and political communities about the progress and success of the service (Pomerants et al., 2006).

In January 2015, a large scale evaluation study was implemented at the libraries of University of Education, Winneba (UEW), Ghana. The goal of the study was to examine the reference service from the user perspective and to understand library users' use/nonuse of the service as well as their perception of the different aspects of the service. The user perspective is crucial in assessing how effective and successful the reference service is because the service mission is to help fulfill library users' information needs and therefore it is imperative to understand how users are using and perceiving the service. Three evaluands may be posited within the timespan of a users's use of reference service: the user's motivation for using the service, the user's perception of the service, and how the user uses the information provided by the service (Pomerantz and Luo, 2006). These three evaluands correspond to the three stages of an individual's movement through a situation, as proposed in Dervin's theory of sense-making (1983). Dervin suggests that the ultimate goal of a user's search for information is to bridge a gap between his internal cognitive state and external reality in order to make sense of the world in addressing some issue or cocern in his life. The gap provides the underlying motivation for the user to seek information from an external source such as the reference service. Under the guidance of Dervin's sense-making theory, our study evaluated how users utilized UEW libraries's reference service in their efforts to bridge the gap, with the focus on the the primary motivation/reasons for them to use the service, and their perception of the service.

In this article, we present a detailed discussion of the implementation, outcome and implications of this study. Thus far there has been limited research about reference evaluation in academic libraries in Africa. Therefore, through a thorough and systematic report of the reference evaluation study at UEW libraries, this article will offer an enriched view of how reference services are provided and utilized in the African context and yield insights for other African academic libraries, or other academic libraries in the developing world, to make informed decisions when planning and implementing their own reference evaluation efforts. 


\section{Background and Literature Review}

The University of Education, Winneba (UEW) was established in 1992 by Ghana's Provisional National Defense Council (PNDC) Law 322 as a University College encompassing seven diploma awarding institutions located in different geographical areas. It became an autonomous institution on May 14, 2004 with the passage of the University of Education Act 672. The mission of the University is to "train competent professional teachers for all levels of education as well as conduct research, disseminate knowledge and contribute to educational policy and development" (http://www.uew.edu.gh/about-us). In the academic year of 2014-15, the university had a student population of 51,686 , among which $74 \%$ were undergraduate students, $19 \%$ were certificate/diploma students, and $7 \%$ were graduate students. There were 1422 faculty members, and $33 \%$ of them were employed full time and $67 \%$ part time.

UEW has five libraries, containing a collection of 110,830 books, 766 print journals and 38,000 online journals from 38 databases, and a seating capacity of 742. There are 60 library employees, out of which 11 are professionals with a Master's degree in library and information science. In four out of the five libraries, the reference desk is titled "Information Help Desk" (IHD) and visibly located near the library entrance with proper signage. In the fifth library, there is no IHD, and users can ask for information help at the Circulation Desk. The opening hours for the IHDs are from 9am to $5 \mathrm{pm}$. The Circulation Desks continue to be available till closing time at $10 \mathrm{pm}$. The IHDs are mainly staffed by professional librarians. Each shift is covered by one librarian. If they have to be absent, the desk will be manned by a paraprofessional temporarily. The Circulation Desks are staffed by paraprofessionals only. When paraprofessionals receive a complex or sophisticated query that requires professional reference expertise, they would convey the query to a librarian and the librarian will follow up with the user.

To prepare for the study and develop the data collection instrument, a comprehensive literature review was conducted. The literature review concentrated on three areas - reference services in Africa, reference service evaluation from the user perspective, and methodologies for user-oriented reference service evaluation.

\subsection{Reference Services in Africa}

The amount of literature about reference services in African libraries is limited. South Africa and Nigeria were the only two countries where published research was located about library reference services. In the 1990s, at the University of South Africa, Dalton (1992) developed a quantitative instrument to measure user satisfaction with the library's subject reference service and tested the instrument among master's and doctoral students. In the early 2000s, as the Internet became more and more popular, Darries (2004) conducted a study among 36 academic libraries in South Africa to examine the impact of the Internet on reference services, focusing on how patron access to the Internet was provided at the libraries and how the Interent was used in supporting and facilitating reference work. Professional preparation of reference librarians was also of interest to authors in South Africa. Penzhorn and Fourie (2004) discussed the challenges in web-based teaching of reference work based on their experiences at the Unitversity of Pretoria and identified the digital divide as a major hurdle in web-based teaching. In a later article, Penzhorn (2007) shared the experience of teaching a course about digital reference that 
aimed at equipping students with the necessary skills and competencies to cope in the digital reference environment.

In Nigeria, the research about reference services was more recent and centered on information technologies. Ola (2010) discussed the limitations faced by the University of Ibadan library in its efforts to deploy Information Communcations Technologty (ICT) to the reference services delivery system, and identified the lack of proper funding, infrastructural deficiencies, inability to retain information technology experts, and intra-local politics as the primary road blocks. Tella and Oyedokun (2014) investigated reference services via social media in selected university libraries in Nigeria. They conducted a survey to ascertain users' awareness, preferences and satisfaction with the service. Findings indicated that Facebook, Twitter and Ask-a-Librarian were ranked as the most preferred methods for dlieveirng online reference services.

Among the small number of studies related to reference services in Africa, only two (Dalton, 1992; Tella and Oyedokun, 2014) were about evaluating reference services. Dalton's (1992) study was more than two dedcades old and was exclusively quantitative with a narrow focus on subject reference service, and Tella and Oyedokun's (2014) study focused on reference services via social media. Our study will further contribute to the literature of reference service evaluation in African libraries by providing a thorough depiction of how users are using and perceiving the reference service at UEW libraries.

\subsection{Reference Service Evaluation from the User Perspective}

The value of evaluating reference service from the user perspective was recognized as early as 1983 , when D'Elia and Walsh (1983) opined that user evaluations were valid indicators of library performance because the subjective perspective focuses on the user as the unit of analysis, and as ultimate consumer of the service outputs, the user is probably the most qualified to evaluate the quality of those outputs. Lancaster (1988) supported this view by stating "the public services of a library must be measured ultimately in terms or user satisfaction". Since then, numerous evaluation studies have been conducted from the users' point of view. For example, Diamond and Sanders' (2006) book provided a collection of reference evaluaton projects and several of the projects engaged users in evaluating reference services in academic libraries.

Amidst the abundant literature of reference evaluation, two books provided a high-level view of the reference evaluation process, including evaluation from the user perspective. Whitlatch's (2000) book discussed the purposes, goals/objectives and measures of reference evaluation, in which four primary types of reference evaluation were identified:

- Economics of reference service, concerning the cost or productivity of reference service variables measured include the number of questions a reference librarian typically answers in an hour, the cost to the library for each reference question answered, the length of time users wait for service, the cost per use of reference information resources, the comparison of cost per use for a printed reference source and cost per use of a similar reference source in electronic format, the length of time users are willing to wait for reference service, the time reference service saves the library user, the time users are willing to devote to the reference service process, the 
value reference service adds to the information the user obtains, the value reference service provides the user in exchange for the additional effort expended, and the cost per query of reference service delivered in different service venues.

- Quality of the reference service process, involving the various aspects of reference encountervariables measured include user satisfaction with the reference encounter, comparison of user satisfaction with reference services in different venues, librarian behavior toward the user, librarian effort in answering the question, librarian knowledge, librarian reference communication skills, user communication skills, user knowledge, level of demand upon the service, and the appropriateness and effectiveness of reference referrals.

- Quality of reference service resources - variables measured include use of print and electronic reference resources, the quality of access systems for major reference sources, the adequacy of reference resources, the adequacy of service hours, comparison of different formats of information, and the effectiveness of various reference staffing arrangements.

- Quality of reference service products, that is, the actual answer or information the user obtained as a result of the service - variables measured include the accuracy of answers users receive, the degree to which users are satisfied with the information provided, the extent to which users report getting the information they needed, the helpfulness of the information in resolving a problem, and the degree to which librarians judge the question to be completely answered.

According to Whitlatch (2000), evaluation from the user perspective mostly appears in measuring "quality of reference service process" and "quality of reference service product". In Saxton and Richardson's (2002) review of the measures that have been used in library reference evaluation, the user perspective was explicitly recognized as one of the two primary angles in reference service evaluation. They stated that most evaluation studies employ either "the query-oriented approach primarily concerned with testing the accuracy of answers to reference" or "the obtrusive user-oriented approach primarily concerned with testing for levels of user satisfaction with the service" (p. 33). They focused on causal relationships and identified the following dependent variables and independent variables:

- Dependent variables - accuracy of, completeness of, usefulness of, and user satisfaction with the information provided as an outcome of reference service

- Independent variables - difficulty and currency of user query, librarian readiness and interest in answering user query, the degree to which librarian understands user query, verification from librarian that user query is fully answered, user's library usage, user's reference service usage, user's education level, librarian's experience, librarian's education level, library's collection size, library's service level, library's service policy

As noted by Saxton and Richardson (2002), the user-oriented approach to reference service evaluation is usually obtrusive. Survey, interview, and focus groups are often used in obtrusive evaluation of reference services from the user perspective. Occasionally, researchers also employ an unobtrusive, "secret-shopper" style method where the researcher or a proxy asks a question as a user so that the 
library does not know that he or she is being observed (Durrance, 1989; Dewdney and Ross, 1994; Pomerantz and Luo, 2006). Dilevko's (2000) book about about unobtrusive reference evaluation provided an in-depth view of this evaluation approach. However, since our study of evaluating UEW library reference service is conducted obtrusively, the review of the methodology literature, presented in the next sub-section, is devoted to obtrusive methods.

\subsection{Methodologies for User-Oriented Reference Service Evaluation}

The identification of appropriate research methodology is essential to a successful evaluation study. As mentioned earlier, in obtrusive evaluation from the user perspective, survey, interview and focus groups are often employed, among which survey is the most popular. Kuruppu (2007) reviewed the literature on reference evaluation methodologies and discussed how each of the three methods, among others, should be used in evaluating reference services. For instance, when discussing the survey method, Kuruppu (2007) covered issues such as survey modality, response rate, the selection of a representative sample, the use of scales, exemplar studies, established instruments, and the inherent weakness of this method.

Whitlatch (2000) pointed out that "surveys are best used if the information desired is something only the individual can provide" (p. 19). Surveys are frequently used in reference evaluation. A well-known survey instrument is the Wisconsin-Ohio Reference Evaluation Program (WOREP). Rimland (2007) documented the history of the WOREP in detail. Originally known in the mid-1980s as the Reference Transaction Assessment Instrument (RTAI), the WOREP was developed by Marjorie Murfin and Gary Gugelchuk (1987) and later Charles Bunge (1999). It measures each reference transaction from the perspective of both the user and the library staff member. Each survey consists of two pages which are divided in half after the user agrees to participate in the study. Both the user and the library complete the survey after the reference transaction, providing ratings of service success and satisfaction with the service (Rimland, 2007).

For more qualitative evaluation, especially regarding complex reference inssues involving users' information seeking behaviors, interviews and focus groups are more suitable alternatives (Flaxbart, 2001). Swope and Katzer (1972) interviewed library users about their reasons for not using the reference desk. Mendelsohn (1997) conducted a series of interviews with library staff and users to understand their definition of reference service quality. Radford (1999) interviewed librarians and users and asked them to recall successful and unsuccessful reference transactions. Overall, although interviews and focus groups provide an evaluative view that's more in-depth and nuanced, they are not nearly as popular as survey in reference evaluation research because of the time and expenses required in conducting and analyzing the interviews.

In our study, survey is used as the data collection as we sought to examine how the reference service at the IHD are perceived and used by library users in general. Our goal was not to obtain an in-depth view of a small group of library users' experience with the IHD, instead, we hoped to understand how the key performance indicators (KPIs) of the IHD are perceived by as many library users as possible. Thus, survey constituted a more appropriate method in our evaluation design. 


\section{Methodology}

We employed the user-oriented approach (Saxton and Richardson, 2002) in the reference service evaluation. Since this was the first reference evaluation study at UEW libraries, we were faced with the decision on how to approach it because there were different evaluation perspectives and focuses. Given the constraints of time and manpower, we could only choose one perspective to concentrate on in this sutdy, and we decided on the user perspective. As discussed in the literature review, the significance of evaluating reference service from the user perspective has been well acknowledged. From the standpoint of UEW libraries, we were also most interested in hearing the voices of the community we serve and learning about how users use and perceive the reference service.

Self-administered paper questionnaires were distributed to users of UEW libraries to study their awareness, use and perception of the Information Help Desk (IHD). The study population was library users in general, who may or may not have used the IHD. Thus, the questionnaire contained a screening question separating the respondents to users and non-users of the IHD. For non-users, reasons for their non-use were inquired about. For users, the focus was on their perception of the quality of the reference service process and the quality of reference service products (Whitlatch, 2000). First, they were asked about their frequency of using the IHD and their reasons for using it. Then, they were asked to indicate their level of agreement with a list of statements measuring the following variables discussed in Whitlatch (2000) and Saxton and Richardson (2002): approachability, friendliness, and communication effectiveness of the librarian; success of the reference encounter; the librarians' capability to efficiently answer the user query, to make proper referrals, to follow up with the user, and to verify that the user's query is completely answered. These variables represented the KPIS of the IHD because they reflected the five areas outlined in the Reference and User Services Association's (RUSA) Guidelines for Behavioral Performance of Reference and Information Service Providers - visibility/approachability, interest, listening/inquiring, searching, and follow-up (http://www.ala.org/rusa/resources/guidelines/guidelinesbehavioral).

In addition, users' willingness to use the service again and to recommend the service to others was also examined. Durrance (1995) established that users' willingness to visit the same librarian at another time avoids the limitations associated with using accuracy as the primary measure of success and should be used as a variable in measuring the success of reference service. Meanwhile, demographic information was collected from both IHD users and non-users.

The study population consisted of users of the five libraries at UEW, including both students and faculty. Due to the lack of access to individual members of this study population, the non-probability sampling method, reliance on available subjects (Babbie, 2012), was employed. In order to mitigate the weakness of a non-probabilistic sample and enhance its representativeness of the study population, we endeavored to reach as many library users as possible. During a three-week period ( $9 \mathrm{am}-10 \mathrm{pm}$ on weekdays, and 9am - 4pm on Saturdays), one thousand questionnaires were distributed to library users upon their arrival at each of the five libraries. They were informed about the study purpose and assured 
that participation in the survey was completely anonymous and voluntary. Completed questionnaires were returned to the IHD or the Circulation Desk.

We recognize that survey as a research method in reference evaluation has its limitations. A survey provides a snapshot which may not be sufficient in capturing the complexity and nuances of the service. Since this survey study was the first endeavor in reference evaluation at UEW libraries, we plan to draw upon the findings to adjust the service accordingly, and conduct another study to examine the impact of the service adjustment. We hope to engage in a longitudinal evaluative effort and incorporate regular evaluation/assessment as part of reference operation. In the long run, trends of how users use and perceive the service will be identified and patters of service usage will be established. This will help us gain an evolving understanding of the reference service's role in assisting faculty and students in their academic pursuit and their respond to the needs of our user community promptly and meaningfully.

\section{Results}

\subsection{User Demographics}

A total of six hundred and thirty-seven questionnaires were returned, representing a response rate of $63.7 \%$. Table $1-3$ provide frequency distributions of the respondents' status, age, and gender. The majority of the respondents were male full-time students, aged from 18 to 25 . The demographic description of the respondents in terms of status was similar to that of the entire population of UEW students as the university had $74 \%$ full time undergraduate students, which was close to the $76.8 \%$ full time students who responded to the survey. This indicates that the sample that completed the survey could still be considered representative of the study population in terms of student status, although it was selected using a non-probability sampling procedure. The other demographic information such as gender and age was collected to present a detailed view of the demographic characteristics of the survey respondents. However, since we did not have access to the description of the student population in terms of gender and age, we were not able to make any comparison on these two variables.

\begin{tabular}{lcc}
\hline & Number\# & Percent\% \\
\hline Full- time Faculty & 52 & 8.2 \\
Part-time Faculty & 28 & 4.4 \\
Full-time Student & 489 & 76.8 \\
Part-time Student & 61 & 9.6 \\
staff & 7 & 1.1 \\
\hline Total & 637 & 100 \\
\hline
\end{tabular}

Table 1. Status of survey respondents

\begin{tabular}{lcc}
\hline & Number\# & Percent $\%$ \\
\hline Under 18 & 8 & 1.3 \\
$18-25$ & 325 & 51.0 \\
$26-35$ & 224 & 35.2 \\
$36-45$ & 59 & 9.3 \\
\hline
\end{tabular}




\begin{tabular}{lcc}
\hline $46-55$ & 17 & 2.7 \\
Over 55 & 4 & 0.6 \\
\hline Total & 637 & 100.0 \\
\hline \multicolumn{3}{c}{ Table 2. Age of survey respondents } \\
\hline Male & Number\# & Percent\% \\
Female & 502 & 78.8 \\
\hline Total & 135 & 21.2 \\
\hline
\end{tabular}

Table 3. Gender of survey respondents

\subsection{Non-use of the IHD}

Among the respondents, $57.4 \%$ have used the IHD at their library, and $42.6 \%$ have not. When asked about the main reason for not using the IHD, most of the non-users ( $43.2 \%, n=271$ ) selected "I'm able to find the information I need myself". The second most popular reason was "I am not aware that the Information Help Desk exists", selected by $38.8 \%$ of the non-users. Following that, $10.6 \%$ chose "I don't want to wait when the librarian is already engaged with somebody else at the desk" and $7.3 \%$ identified with "I don't feel comfortable talking to librarians".

\subsection{Use of the IHD - Frequency and Motivations}

Respondents were asked how frequently they used the IHD in the past six months, and as shown in Table 4, a little more than half used it between one to five times. It's worth noting that close to $9 \%$ of them used it more than 20 times. It's necessary to note that the study sample only consisted of students and faculty that visited the library physically and those who did not use the library were excluded. This might explain the relatively hight usage frequency because existing library users are more likely to be veteran users of various library services.

\begin{tabular}{lcc}
\hline & Number\# & Percent $\%$ \\
\hline 1 to 5 times & 184 & 50.3 \\
6 to 10 times & 83 & 22.7 \\
11 to 20 times & 67 & 18.3 \\
More than 20 times & 32 & 8.7 \\
\hline Total & 366 & 100.0 \\
\hline
\end{tabular}

Table 4. Frequency of using the Information Help Desk

Regarding their motivations to use the IHD, each respondent was asked to select up to two reasons. Table 5 indicates that "I need help with class assignments" and "I need help to find information for personal interests" were the two most popular factors that motivated the respondents' use of the IHD.

\begin{tabular}{lcc}
\hline & Number\# & Percent\% \\
\hline I need help with class assignments. & 247 & 38.8 \\
I need help to find information for personal interests. & 195 & 30.6 \\
\hline
\end{tabular}




\begin{tabular}{lll}
\hline I need help with using the library facilities such as computers, printers and study & 185 & 29.0 \\
rooms. & 70 & 11.0 \\
Ineed help with a research project for which I'm a student assistant. & 40 & 6.3 \\
I need help with a research project for which I'm the principal investigator. & 22 & 3.5 \\
My instructor requires that we talk to librarians about our assignments. &
\end{tabular}

Table 5. Motivations of using the Information Help Desk

\subsection{Use of the IHD - Perception of the Service}

Respondents were asked to indicate their level of agreement with an array of statements that measure variables related to the quality of the reference service process and the quality of reference service products (Whitlatch, 2000), based on their overall experience of using the IHD. The list below delineates which variables are measured by which statements:

1. Librarian's approachability - "The librarian is approachable" (Area 1 in RUSA Behaviorial Guidelines: Visibility/Approachability)

2. Librarian's friendliness - "The librarian is friendly" (Area 1 in RUSA Behaviorial Guidelines: Visibility/Approachability)

3. Librarian's communication effectiveness - "The librarian listens to my question attentively"; (Area 2 and 3 in RUSA Behaviorial Guidelines: Interest, Listening/Inquiring ) "The librarian is able to effectively clarify what I'm looking for" (Area 3 in RUSA Behaviorial Guidelines: Listening/Inquiring)

4. Librarian's capability to efficiently answer the query - "The librarian answers my question in a timely manner" (Area 4 in RUSA Behaviorial Guidelines: Searching)

5. Librarian's capability to make proper referrals - "The librarian refers me to sources outside of the library when he/she couldn't fully answer my question" (Area 4 in RUSA Behaviorial Guidelines: Searching)

6. Librarian's capability to follow up with the user - "The librarian promises to get back to me when he/she couldn't fully answer my question" (Area 5 in RUSA Behaviorial Guidelines: Follow-up)

7. Librarian's capability to verify the fulfillment of user needs - "The librarian ensures that my question has been satisfactorily answered at the end of our conversation" (Area 5 in RUSA Behaviorial Guidelines: Follow-up)

8. Overall success of the reference encounter - "The librarian successfully helps me with my question"

9. User's willingness to return to the service - "I would use the Information Help Desk again"

10. User's willingness to recommend the service - "I would recommend the Information Help Desk to others"

For each statement, respondents were asked to rate their level of agreement on a five-point scale, with 1 being "Strongly Disagree", and 5 being "Strongly Agree". This scale was an interval scale since only the two ends were anchored, and thus the mean value could be calculated for each statement. Table 6 lists the mean value of respondents' level of agreement with each statement, as well as the percentage of 
respondents that selected "Not Applicable (N/A)" regarding each statement. The two statements that received the highest level of agreement were "I would recommend the Information Help Desk to others" and "I would use the Information Help Desk again" (both were above 4), indicating that respondents' overall experience of using the IHD was positive. The ones that respondents most disagreed with were "The librarian refers me to sources outside of the library when he/she couldn't fully answer my question" and "The librarian promises to get back to me when he/she couldn't fully answer my question" (both were below 3), suggesting that they were not satisfied with these two aspects of their reference encounters - librarians making proper referrals and following up with users.

\begin{tabular}{lcc}
\hline \multicolumn{1}{c}{ Statement } & $\begin{array}{c}\text { Mean value of the } \\
\text { level of agreement }\end{array}$ & $\begin{array}{c}\text { Percentage } \\
\text { of N/A \% }\end{array}$ \\
\hline I would recommend the Information Help Desk to others. & 4.14 & 37.7 \\
I would use the Information Help Desk again. & 4.11 & 38.3 \\
The librarian is friendly. & 3.94 & 36.1 \\
The librarian listens to my question attentively. & 3.93 & 35.5 \\
The librarian is approachable. & 3.78 & 59.9 \\
The librarian is able to effectively clarify what l'm looking for. & 3.62 & 33.4 \\
The librarian ensures that my question has been satisfactorily answered & 3.52 & 32.3 \\
at the end of our conversation. & & 33.4 \\
The librarian successfully helps me with my question. & 3.41 & 32.7 \\
The librarian answers my question in a timely manner. & 3.32 & 25.6 \\
The librarian refers me to sources outside of the library when he/she \\
couldn't fully answer my question.
\end{tabular}

Table 6. Perceptions of the different aspects of the Information Help Desk

\subsection{Ideas for Improving the IHD}

The final question on the survey was an open-ended question, where respondents were asked to provide ideas for improving the IHD. A total of 191 respondents answered this question, and from their responses, twelve themes were synthesized. The parenthesized percentage indicates the percentage of the 191 respondents that suggested each idea.

- Librarians at the IHD need to have better customer service skills, such as friendliness, approachability, patience, attentiveness, clear communication skills, and punctuality. (28.9\%)

- More and better facilities are needed at the library, such as stable supply of electricity, faster internet, more computers/printers/photocopiers, and more desks and chairs. (22.2\%)

- The scope and content of library resources need to be improved - respondents identified several subject areas where relevant and current books were needed, such as environmental health and sanitation, information communications and technology, and Arabic language. (13.9\%) 
- The IHD service needs to be expanded to better meet user needs - respondents suggested that more librarians be available to answer questions during each shift, the service hours be extended, and more service locations (even outside of the library) be offered. (13.3\%)

- Librarians at the IHD need to be better prepared and motivated - training is necessary to equip the librarians with the skills and knowledge they need, the IHD itself should be furnished with easily accessible reference collections and laptops, and proper incentives should be offered to motivate librarians to work at the IHD. (11.7\%)

- Better marketing is needed to make the IHD and other library resources known to students and faculty - some respondents specifically mentioned the use of the notice board in front of the library as a way to inform users about library updates. (8.9\%)

- Librarians need to improve the quality, such as the accuracy, completeness, and timeliness of the answers they provide to user queries. (5.0\%)

- Librarians need to provide information literacy instruction to students. (3.9\%)

- Library resources need to be better organized so that users can easily access them. (3.9\%)

- A suggestion box is needed for users to provide their feedback to the library. (2.2\%)

- Better security is needed to monitor the activities in the library. (2.2\%)

- Longer loan periods for library books are needed. (1.1\%)

\section{Discussion and Conclusion}

Findings of the survey study yield a thorough understanding of how UEW library users use and view the library reference services provided at the Information Help Desk (IHD). It was alarming that the IHD nonuse rate was $42.6 \%$, and close to $40 \%$ of the non-users did not use the service because they were not aware of its existence. This statistic speaks clearly to the need for aggressive marketing of the IHD and its services to UEW students and faculty. More effective marketing is also suggested in the survey responses as a way to improve the IHD. Ideas that may help make the IHD known to library users include 1) clear signage that directs users to the IHD;2) clear explanations of how the IHD works via various kinds of marketing materials; and 3) word of mouth advertisement by librarians whenever they interact with library users. It is also worth noting that $7.3 \%$ of the non-users averted using the service because they do not feel comfortable talking to librarians. This may have resulted from their negative experiences when approaching librarians in the past, or their own personality. Further efforts are needed to discern the exact causes of their discomfort, and thus actions can be taken to address them properly. One notion brought up by the survey respondents was to provide a suggestion box for users to submit their feedback to the library so that library resources and services can be improved. Such a suggestion box allows library users to share their thoughts and ideas freely and anonymously, and offers a convenient venue for the library to glean input from the user community. However, the suggestion box cannot be an empty gesture, and the library needs to reveal to users their commitment to listening to the voices of library users through regular updates about how users' feedback in the suggestion box has been addressed.

The top three motivations for library users to use the IHD are class assignments, personal interests, and using library facilities. Close to $40 \%$ of the survey respondents indicated that they used the IHD when in 
need of help with their class assignments. This is the most popular reason driving library users to use the IHD. On one hand, it validates the main mission of the IHD, which is to support students' academic studies. On the other hand, there is still much room for progress in terms of encouraging students to approach the IHD for assignment assistance. The survey respondents pointed out that the IHD librarians' customer service skills still need improvement. This indicates that students will be more likely and willing to seek assignment help at the IHD if the librarians are more friendly, approachable, patient, attentive and punctual.

It is also interesting to note that personal interests is the second most popular motivation, prompting $30.6 \%$ of the survey respondents to use the IHD. This is auspicious and shows that students and faculty trust the IHD with their personal information needs. This trend should be encouraged with the assurance that confidentiality is guaranteed for information they seek from the IHD for their personal consumption. The third most popular motivation, using library facilities, was selected by $29 \%$ of the survey respondents, indicating that a significant amount of IHD librarians' time is spent on addressing users' technical questions. If this continues and becomes a concern, a different staffing model may need to be considered to optimize the use of the librarian's expertise and time. For example, multiple types of staff may be arranged to answer user queries. Paraprofessionals or trained students may staff the reference desk alongside librarians, and they are responsible for answering simple queries like directional and technical questions and refer more complex queries to reference librarians.

Regarding library users' perception of various components of their reference encounters at the IHD, the overall altitude is positive. The survey respondents expressed a strong tendency to use the IHD again and to recommend it to someone else. This is also confirmed by their suggestion to expand the IHD services through longer hours, extra manpower and more locations. Based on the survey responses, the IHD librarians seemed to be more successful at exhibiting customer service qualities like friendliness and attentiveness than performing tasks related to identifying users' information needs and searching/locating relevant information to fulfill the needs. The weakest area appears to be handling queries that could not be directly answered during the reference encounter, such as following up with users at a later time or making proper referrals. This finding provides us with a concrete understanding of how the different aspects of the IHD services are viewed by library users. It will help us identify the service areas where improvements are most needed and develop necessary training programs to address them. For instance, priority may need to be given to librarian training that focuses on enhancing their knowledge of information resources and search skills.

In terms of the limitations of the study, we recognize that the study sample was selected using a nonprobability sampling design, even though even the sample was similar to the study population in terms of the distribution student status. The questionnaires were distributed to students and faculty who came to the library, introducing a bias against those who were less likely to visit the library. In future evaluation studies, we would consider employing a probability sampling design to yield a more representative sample. Also, since the objective of the study was examining UEW library users' use/nonuse and perception of the reference service, the data analysis focuses on univariate descriptive statistics. In the future, we would consider adding more correlational analysis to identify the relationships between different variables and utilizing qualitative approaches to unearth nuanced details of users 
information behavior (e.g. differences between those using the service only once and those using it multiple times).

In conclusion, this study delivers an in-depth examination of UEW libraries' reference services from the user perspective. The knowledge gained from this study deepens our understanding of how the services are experienced and perceived by library users and offers insights on how to improve the services to better meet user needs. As shown in the literature review, there has been limited research on reference evaluation in African academic libraries, and our study will contribute to the growth of knowledge in that area and help strengthen the literature. The survey instrument used in the study, particularly the questions measuring KPIs based on the RUSA Behavioral Guidelines, may be of use to other libraries who are also interested in assessing the same KPIs. They may replicate the study by directly using our survey questionnaire, and their results can be compared against ours to present a nuanced view of reference evaluation across different contexts. Other libraries in Africa or in developing countries with characteristics similar to ours may also find our study useful, informative and applicable to their own situations. Furthermore, through the detailed reporting this study, we hope to help other academic libraries in Africa successfully plan and implement their own reference evaluation studies, and ultimately encourage more evidence-based library practices in the developing world.

\section{References}

Babbie, E. (2012). The Practice of Social Research, $13^{\text {th }}$ ed., Wadsworth, Belmont, CA.

Bunge, C. (1999), "Gathering and using patron and librarian perceptions of question-answering success", The Reference Librarian, Vol. 66, pp. 115-140.

Dalton, G. (1992), "Quantitative approach to user satisfaction in reference service evaluation", South African Journal of Library and Information Science, Vol. 60 No. 2, pp. 89-103.

Darries, F. (2004), "Internet access and use in reference services in higher education institutions in South Africa", South African Journal of Library and Information Science, Vol. 70 No. 2, pp. 72-85.

D’Elia, G. and Walsh, S. (1983), “User satisfaction with library service: A measure of public library performance”, Library Quarterly, Vol. 53 No. 2, pp. 109-133.

Dervin, B. (1983, May). An overview of sense-making research: concepts, methods, and results to date. Paper presented at the annual meeting of the International Communication Association, Dallas, TX.

Dervin, B. (2003). From the mind's eye of the user: The sense-making qualitative-quantitative methodology. In B. Dervin, L. Foreman-Wernet, \& E. Lauterbach (Eds.), Sense-making methodology reader: Selected writingsof Br enda Dervin (pp. 270-292). Cresskill, NJ: Hampton Press.

Dewdney, P. and Ross, C. S. (1994), "Flying a light aircraft: Reference service evaluation from a user's viewpoint", $R Q$, Vo. 34 No. 2, pp. 217-229.

Dilevko, J. (2000), Unobtrusive Evaluation of Reference Service and Individual Responsibility, Ablex Publishing Corporation, Wesport, CT. 
Diamond, T. and Sanders, M. (2006), Reference Evaluation and Assessment, Routledge, London, UK.

Durrance, J. C. (1989), “Does the 55 percent rule tell the whole story?”, Library Journal, Vol. 114 No. 7, pp. 31-36.

Durrance, J. C. (1995), "Factors that influence reference success: What makes questioners willing to return?" Reference Librarian, Vol. 49/50, pp. 243-265.

Flaxbart, D. (2001), "Conversations with chemists: Information seeking behavior of chemistry faculty in the electronic age", Science and Technology Libraries, Vol. 21 No. 3/4, pp. 5-26.

Kuruppu, P. U. (2007), "Evaluation of reference services: A review", Journal of Academic Librarianship, Vol. 33 No. 3, pp. 368-381.

Lancaster, F. W. (1988), If you want to evaluate your library..., Library Association, London, UK.

Mendelsohn. (1997), "Perspectives on quality of reference service in an academic library: A qualitaty study", $R Q$, Vol. 36 No. 4, pp. 544-557.

Murfin, M. E. and Gugelchuk, G. M. (1987), “Development and testing of a reference transaction assessment instrument", College and Research Libraries, Vol. 48 No. 4, pp. 314-339.

Ola, C. O. (2010), "Reference service delivery system in West Africa: Limitations and prospects as seen from Kenneth Dike Library, University of Ibadan, Nigeria”, Internet Reference Services Quarterly, Vol. 15, pp. 97-106.

Penzhorn, C. (2007), "Training for digital reference: A South African experience", Libri, Vol. 57, pp. 76-83.

Penzhorn, C. and Fourie, I. (2004), "Challenges in web-based teaching of reference work: Experiences at the University of Pretoria", Mousaion, Vol. 22 No. 1, pp. 70-88.

Pomerantz, J. and Luo, L. (2006), "Motivations and uses: Evaluating virtual reference service from the users' perspective", Library \& Information Science Research, Vol. 28 No. 3, pp. 350-373.

Pomerantz, J., Luo L. and McClure, C. R. (2006), "Peer review of chat reference transcripts: Approaches and strategies", Library \& Information Science Research, Vol. 28 No. 1, pp.24-48.

Radford, M. (1999), The Reference Encounter: Interpersonal Communication in the Academic Library, Association of College and Research Libraries, American Library Association, Chicago, IL.

Rimland, E. L. (2007), "Do we do it well? A bibliographic essay on the evaluation of reference effectiveness", The Reference Librarian, Vol. 47 No. 2, pp. 41-53.

Saxton M. L. and Richardson, J. V. Jr. (2002), Understanding Reference Transactions: Transforming an Art into a Science, Academic Press, San Diego, CA. 
Swope, M. and Katzer, J. (1972), "Silent majority: Why don't they ask questions", RQ, Vol. 12, pp. 161166.

Tella, A. and Oyedokun, T. T. (2014), "An evaluation of online reference services through social networking sites in selected Nigerian university libraries", The Reference Librarian, Vol. 55, pp. 343-367.

Whitlatch, J. B. (2000), Evaluating Reference Services: A Practical Guide, American Library Association, Chicago, IL. 